\title{
Delineation of a volcanic ash body using electrical resistivity profiling
}

\author{
Jianghai Xia ${ }^{1,3}$, Greg Ludvigson ${ }^{1}$, Richard D Miller ${ }^{1}$, \\ Lindsay Mayer ${ }^{1,4}$ and Adel Haj ${ }^{2}$ \\ ${ }^{1}$ Kansas Geological Survey, The University of Kansas, 1930 Constant Ave., Lawrence, KS 66047, USA \\ ${ }^{2}$ Department of Biology and Earth Science, University of Central Missouri, Warrensburg, MO 64093, \\ USA \\ E-mail: jxia@kgs.ku.edu
}

Received 18 December 2009

Accepted for publication 28 April 2010

Published 9 June 2010

Online at stacks.iop.org/JGE/7/267

\begin{abstract}
Four lines of electrical resistivity profiling (ERP) were performed to define the extent of a shallow Quaternary volcanic ash deposit being mined in the United States. Inversion results of ERP proved suitable for defining the thickness and lateral extent of the volcanic ash deposit at this testing site. These interpretations were confirmed by shallow borehole drilling. The model sensitivity information indicates that inverted models possess sufficient resolving power down to a depth of $7 \mathrm{~m}$ and are fairly consistent in terms of horizontal resolution along the four ERP lines. The bottom of most of the volcanic ash deposit in the study area is less than $7 \mathrm{~m}$ in depth. Based on synthesis of the ERP and drill information, the limits of the mineable ash bed resources were clearly defined. Moreover, by integrating the ERP results with a minimal number of optimally placed borings, the volume of the volcanic ash deposit was established at a lesser cost, and with greater accuracy than would be possible with a traditionally designed grid drilling programme.
\end{abstract}

Keywords: volcanic ash, electrical resistivity profiling, core drilling

\section{Introduction}

Volcanic ash production in the central Unites States has not lived up to its potential since limited production began in the early 1900s. Between 1920 and 1940 this region was the largest producer of volcanic ash products in the Unites States. Since 1945 , commercial production has steadily declined and in 1960 only two producers remained. Applications and therefore markets exist for both raw and popped or bloated ash products. Uses for refined ash include filtrate media, plaster wallboard, thermal (low temperature) insulation and lightweight fireproof acoustic tile. Markets for raw ash include ceramic components, glass products, mild abrasives, road construction, concrete aggregate, and a component of granular fertilizer. Both bloated and raw ash have been used as oil and grease absorbents and inert filters.

\footnotetext{
3 Author to whom any correspondence should be addressed.

${ }^{4}$ Present address: Chevron Corporation, 1400 Smith St Ste 3600, Houston, TX 77002, USA
}

Exploitation of volcanic ash deposits currently mined in the central United States has been limited to sparse subsurface data from drill cuttings and exposures in shallow pit walls. Continued extraction of ore from operating mines has been guided by operator observations of successive fresh exposures that appear during the mining process, interpolated to the nearest drill hole with cuttings. However, before this near-surface product can be marketed, viable means must be developed for estimating volumes, geometries and characteristics of the ash deposits. Most important is the development of cost-effective techniques for locating, sampling (for assay) and delineating volcanic ash deposits with great enough certainty to allow accurate resource projections that are needed for securing long-term contracts based on known reserves and thereby deliverable product. To ensure the highest accuracy and reliability of these estimations, drill holes need to be optimally placed to allow reliable interpretations from these borings within a threshold percentage. 
With so little known about the site-specific geology and characteristics of most ash bodies as well as the overburden and basal contact, an integrated geophysical (electrical resistivity, magnetic and ground penetration radar) survey with borehole verifications was carried out in order to ascertain which methods would contribute the most costeffective and informative data for searching out these ore bodies. Geophysical test data and borehole samples were acquired at sites in close proximity to an existing mine face to evaluate the effectiveness and develop an optimized approach incorporating geophysics and drilling. Of the three geophysical surveys completed, electrical resistivity profiling mated with continuous borehole sampling provided the most encouraging results in delineating volcanic ash bodies.

Two-dimensional (2D) electrical resistivity profiling (ERP) at the surface is normally used to estimate the subsurface electric resistivity distribution by taking measurements along a survey line. Each measurement generally requires electrical current to be injected into the ground through two currentcarrying electrodes with voltage measurements taken at two potential electrodes some specific distance away. An apparent resistivity is calculated using the injected current, the measured voltage and a geometric factor related to the arrangement of the four electrodes (Zohdy et al 1974, Reynolds 1997). The maximum investigation depth of electrical resistivity depends generally on the spacing of the current injecting electrodes and on geometry and conductivity of geologic materials. Therefore, sampling different depths can be accomplished by changing the electrode spacing. Individual measurements are taken along a survey line using various combinations of electrodes and spacings to produce an apparent resistivity cross section. Apparent resistivity is an averaged value with contribution from both horizontal and vertical directions effectively reducing resolution of ERP results with increasing investigation depths. The main advantages of 2D ERP are its simplicity and low cost in data acquisition and instruments. It must be recognized, however, that current flows in a 3D earth and a 2D resistivity imaging technique would be more likely to produce false anomalies because the objects which did not intersect the imaging plane would be folded onto the 2D inverted cross section (Yang and Lagmanson 2006).

Apparent resistivity data are then inverted to obtain estimated resistivity models that practically increase the resolution of the resistivity model and allow interpretation of the subsurface distribution of resistivity. If the relationship between resistivity and materials is known at the site, then structure and stratigraphy may be inferred from the model of resistivity (Wolfe et al 2000, deGroot-Hedlin and Constable 1990, Edwards 1977, Oldenburg and Li 1999, Tsourlos et al 1999, Loke 2001). Many geological/environmental and cultural factors affect or control the apparent measured resistivity of the subsurface; some of these factors include the composition of the subsurface materials, the amount of water in the subsurface and the ionic concentration of the pore fluid. Electrical resistivity models are commonly used to identify, delineate and map subsurface features such as electrically conductive contamination plumes, bedrock fracture zones, the saltwater/freshwater contact, the vadose zone, sulfide and

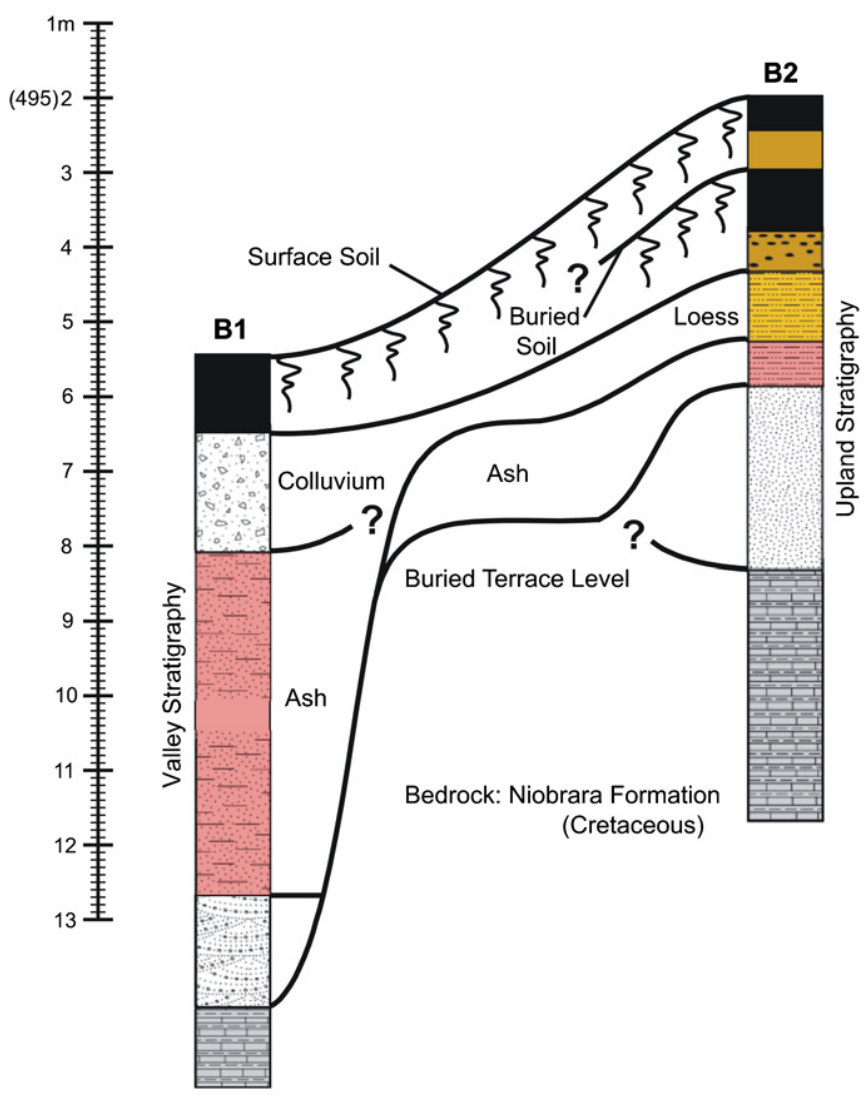

Figure 1. Borehole logs at the mine site, with interpretations of sedimentologic and stratigraphic relationships between the deposits. Steep boundaries limiting the extent of the ash deposits are buried cutbank scarps.

other conductive ores, electrically conductive lithologic units such as clay and sediment size distribution (Dawson et al 2002, Behiry and Hanafy 2000, Benson et al 1997).

This feasibility study was encouraged by successfully defining a subsidence feature by the ERP (Xia and Miller 2007). This study employed the use of ERP to delineate a volcanic ash body in the site primarily focusing on the question of how well the volcanic ash at this site, known to be present from drill and quarry samples, could be delineated beneath several metres of soil.

\section{Site geology}

Drillcore 1 (B1) near the western end of the studied area was drilled several metres back from the position of the mine high wall. This drillcore penetrated $4.5 \mathrm{~m}$ of volcanic ash-the ore body being mined at the site (figure 1). Following field studies were carried out along the high wall. This field sampling also produced high quality samples of the ash bed sedimentology through the quarrying of sediment sample monoliths that will be the subjects of subsequent laboratory studies.

Drillcore 2 (B2) near the eastern end of the studied area was drilled several metres from a fence line that delimits the leased property for mining activity. This drillcore penetrated less than $1 \mathrm{~m}$ of impure volcanic ash, clearly showing that 


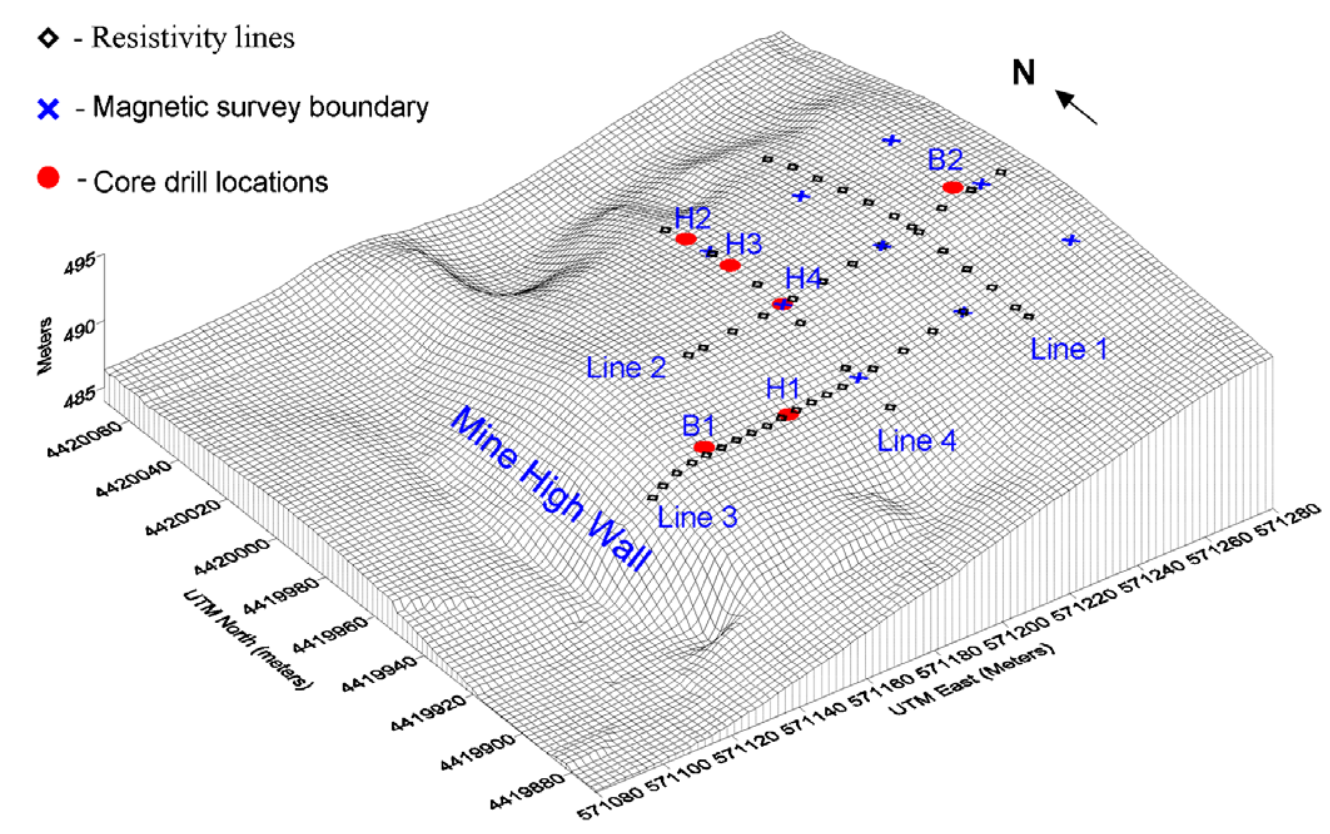

Figure 2. Contour net diagram depicting surface elevation with locations of drill holes and geophysical survey data coordinates.

mineable ash bed resources do not extend throughout the whole extent of the leased property (figure 1).

Figure 1 also shows interpretations of the sedimentologic and stratigraphic relationships among the three observation points at the mine site discussed above, also integrated with results from later drilling and electric resistivity profiling. The mined ash bed is interpreted to be a valley-filling deposit of stream and ponded volcanic ash sediments that were eroded from the primary direct air-fall volcanic ash sediments that were originally deposited in upland positions on the landscape. These later stream-related processes led to a thickening of volcanic ash sediments at their sites of secondary deposition. The succession of alluvial (stream-laid) sediments accumulated on a valley floor that was inset (cut by a stream incision) from the upland stratigraphy shown by B2 (figure 1).

One local complication in the site geology relates to the distribution of colluvial deposits that are exposed above the ash deposit at the northern end of the mine high wall. This colluvium consists of fragments of weathered cretaceous chalk and cretaceous marine mollusk fossils all within a sandy matrix. These deposits were weathered and transported from the local cretaceous bedrock in higher landscape positions above the mine site. They were also encountered in drillcore $\mathrm{B} 1$ and borehole $\mathrm{H} 4$, where they apparently truncated the thin ash deposits on the buried terrace level (figure 1) in a small buried gully that cut through and locally removed the ash deposits.

\section{Electric property of volcanic ash}

Based on chemical analyses of 54 volcanic ash samples from around the studied region, the chemical composition of volcanic ash from the various deposits is remarkably uniform. Fresh volcanic ash samples commonly contain more than $70 \%$ silica $\left(\mathrm{SiO}_{2}\right)$, approximately $12 \%$ alumina $\left(\mathrm{Al}_{2} \mathrm{O}_{3}\right), 2 \%$ ferric oxide $\left(\mathrm{Fe}_{2} \mathrm{O}_{3}\right), 7 \%$ alkalies and generally less than $3 \%$ lime $(\mathrm{CaO})$ and magnesia $(\mathrm{MgO})$. Volcanic ash mainly consists of silica and alumina based on these findings. The electrical resistivities of silica and alumina are $2 \times 10^{14} \Omega \mathrm{m}$ (Olhoeft $1981)$ and $1 \times 10^{14} \Omega \mathrm{m}$ (Chakravarty et al 2005$)$, respectively. The electrical resistivity of topsoil in the study area is around $20 \Omega \mathrm{m}$ (Lund et al 2000). Due to a higher moisture level, colluvial deposits also show much lower resistivity. With the extremely high electrical resistivity contrast in the studied region, we expect anomalies with higher electric resistance for volcanic ash than for surrounding materials. However, variations in composition due to contaminants such as clay and iron oxide could complicate the volcanic ash's resistivity signature. Borehole information was necessary to calibrate resistivity values associated with volcanic ash and verify interpretations based on resistivity anomalies.

\section{Electric resistivity surveys and core drilling}

ERP surveys were performed along four $94.5 \mathrm{~m}$ lines on two different trips to the site using a Jilin University Geopen ${ }^{\mathrm{TM}}$ E60C multi-electrode resistivity meter with 64 electrodes at $1.5 \mathrm{~m}$ intervals using a Wenner array acquisition approach. The resistivity meter systematically and automatically selects current electrodes and measurement electrodes to sample. The investigation volume (and hence depth) increases with increasing distance between electrodes. The maximum investigation depth for this array was around $15 \mathrm{~m}$ to $20 \mathrm{~m}$ (1/6 to $1 / 5$ of the profile length (Bernard and Leite 2004)). A Wenner array possesses a balance among vertical resolution, investigation depth and acquisition noise. Data for lines 1 and 
2 were acquired during the first trip to the site with the goal to uniquely measure the electrical signature of volcanic ash. Line 1 is north/south and located at the east end of the survey site with the station at $27 \mathrm{~m}$ intersecting the east/west line 2 at the station at $52.5 \mathrm{~m}$. During the data acquisition component of the first trip, two boreholes (B1 and B2) were drilled and sampled (figure 2).

\section{Stage 1}

ERP surveys were performed along two $94.5 \mathrm{~m}$ lines (lines 1 and 2, figure 2). The surface electric resistivity was relatively uniform and low, making surveys much faster than expected and the data quality high. Measured apparent resistivity data were in a range of 20 to $80 \Omega \mathrm{m}$.

Measured apparent resistivity data were inverted using EarthImager $^{\mathrm{TM}}$ (AGI 2005). Topographic correction is not applied to data because the ground surface of the survey site is generally flat and the largest slope along each line is less than $5^{\circ}$, which is much smaller than the recommended criterion for topographic correction $\left(>10^{\circ}\right)$ that is determined by numerical modelling (Hennig et al 2005). We selected a smooth model inversion algorithm with the default initial model. Selection of the final inverted models was based on the maximum derivative change of the root-mean-square error with respect to the iteration number. Figures 3(a) and 4(a) show measured apparent resistivity data used as inputs for the inversion. Figures $3(b)$ and $4(b)$ show calculated apparent resistivity due to the inverted resistivity models shown in figures $3(c)$ and $4(c)$, respectively. Calculated apparent resistivity data generally fit the measured apparent resistivity data maintaining a relative RMS error between 1.8 and $2.3 \%$.

Borehole B2 was located $3 \mathrm{~m}$ north of the station at $15 \mathrm{~m}$ on line 2. The borehole geology validated the ERP measurements. A $0.75 \mathrm{~m}$ thick layer of ash was encountered at a depth of $3.6 \mathrm{~m}$, suggesting that the high resistivity layer (reddish colour in figures $3(c)$ and $4(c)$ ) could be indicative of volcanic ash at this site. Based on the resistivity data, this layer of volcanic ash appears to thicken to the west (figure 4(c)). Using the interpretation of line 2 as a guide, the ERP image along line 1 appears to suggest that the volcanic ash layer is discontinuous in the north-south direction (figure $3(c)$ ). To confirm these interpretations and tie more ERP images with borehole B1, two more electric resistivity profiles were acquired during the second stage.

\section{Stage 2}

Data along lines 3 and 4 were acquired during stage 2 of this project to verify consistency and to extend resistivity anomalies interpreted on line 3, and confirmed in borehole $\mathrm{B} 1$ at the station at $75 \mathrm{~m}$ (figure 2). A $4.5 \mathrm{~m}$ thick layer of ash was encountered in borehole B1 beginning at a depth of $2.7 \mathrm{~m}$. Line 3 was an east to west profile with the mine face at the extreme west end of the line, and intersecting line 4 at the station at $30 \mathrm{~m}$. Line 4 was a north to south profile, perpendicular to line 3 , and tied with line 2 at the station at $52.5 \mathrm{~m}$ and line 3 at the station at $52.5 \mathrm{~m}$ (figure 2). The same data acquisition parameters were used to collect these resistivity data as previously on lines 1 and 2 . The electrical conditions of the ground were generally the same during the acquisition of lines 3 and 4 as when data were collected along lines 1 and 2. Measured apparent resistivity data ranged from 20 to $80 \Omega \mathrm{m}$ and were consistent with data acquired during stage 1 (figures 5(a) and 6(a)). The same inversion processing approach and initial model were used on lines 3 and 4 data as on lines 1 and 2. Figures $5(b)$ and $6(b)$ display calculated apparent resistivity based on the inverted resistivity models shown in figures 5(c) and 6(c), respectively.

A higher resistivity layer apparent at the station of $63 \mathrm{~m}$ of line 3 correlates extremely well with mined volcanic ash exposed in the high wall (figure $5(c)$ ). Ground truth for line 3 was provided by borehole $\mathrm{B} 1$, which was located at the station at $75 \mathrm{~m}$. One distinguishing feature of this profile (figure $5(c)$ ) is the abrupt termination of the higher resistivity layer around the station at $60 \mathrm{~m}$. This suggests that the volcanic ash body as imaged beneath line 3 ends around that station, which is different from what was learned from ERP results of line 2, $30 \mathrm{~m}$ north of line 3 . The inverted resistivity model of line 4 (figure 6(c)) also suggests that this thin layer of volcanic ash terminates to the west around the station at $12 \mathrm{~m}$.

An investigation depth determined by $1 / 6$ to $1 / 5$ of a profile length (Bernard and Leite 2004) does not mean that an inverted model reveals geology at the depth. The model sensitivity of the inversion system is critical to confident interpretation of the inverted model. Estimation of depth of investigation can be calculated using the algorithm proposed by Oldenburg and Li (1999) or the model sensitivity matrix. We used information directly provided by EarthImager ${ }^{\mathrm{TM}}$ (AGI 2005) in our data processing. Pseudo model sensitivity (figure 7) is the diagonal element of the sensitivity matrix $\left(\mathbf{J}^{\mathrm{T}} \mathbf{J}\right)$, where $\mathbf{J}$ is the Jacobian matrix (AGI 2005). The sensitivity matrix is an approximation to the model resolution matrix (Wiggins 1972) for our sparse inversion system with a large number of unknowns. The model sensitivity information indicates that inverted models (figures 3(c), 4(c), 5(c) and 6(c)) possess sufficiently resolving power down to a depth of $7 \mathrm{~m}$ and are pretty consistent in terms of horizontal resolution along the four lines, where the bottom of most volcanic ash bodies in the study area lies.

Inverted resistivity models from the four profiles incorporated with borehole locations (figure 8) were used to generate the resistivity model fence diagrams to provide a pseudo 3D image of the volcanic ash layer viewing from two directions (figure 9). Tie points along the profiles correlated extremely well and did not require any depth adjustment to create the inverted resistivity model fence diagram. An approximation boundary of the cutbank bounding the thick ash deposit and buried ash determined by the inversion of ERP data were superposed in figure 9.

\section{Additional borehole verification and discussion}

To further confirm our interpretation and obtain the ground truth, four additional boreholes were drilled $(\mathrm{H} 1, \mathrm{H} 2, \mathrm{H} 3$ and $\mathrm{H} 4$, figure 2). Borehole $\mathrm{H} 1$ was drilled around the station at $50.25 \mathrm{~m}$ of line 3 and reached the total depth (TD) at $7.5 \mathrm{~m}$. 

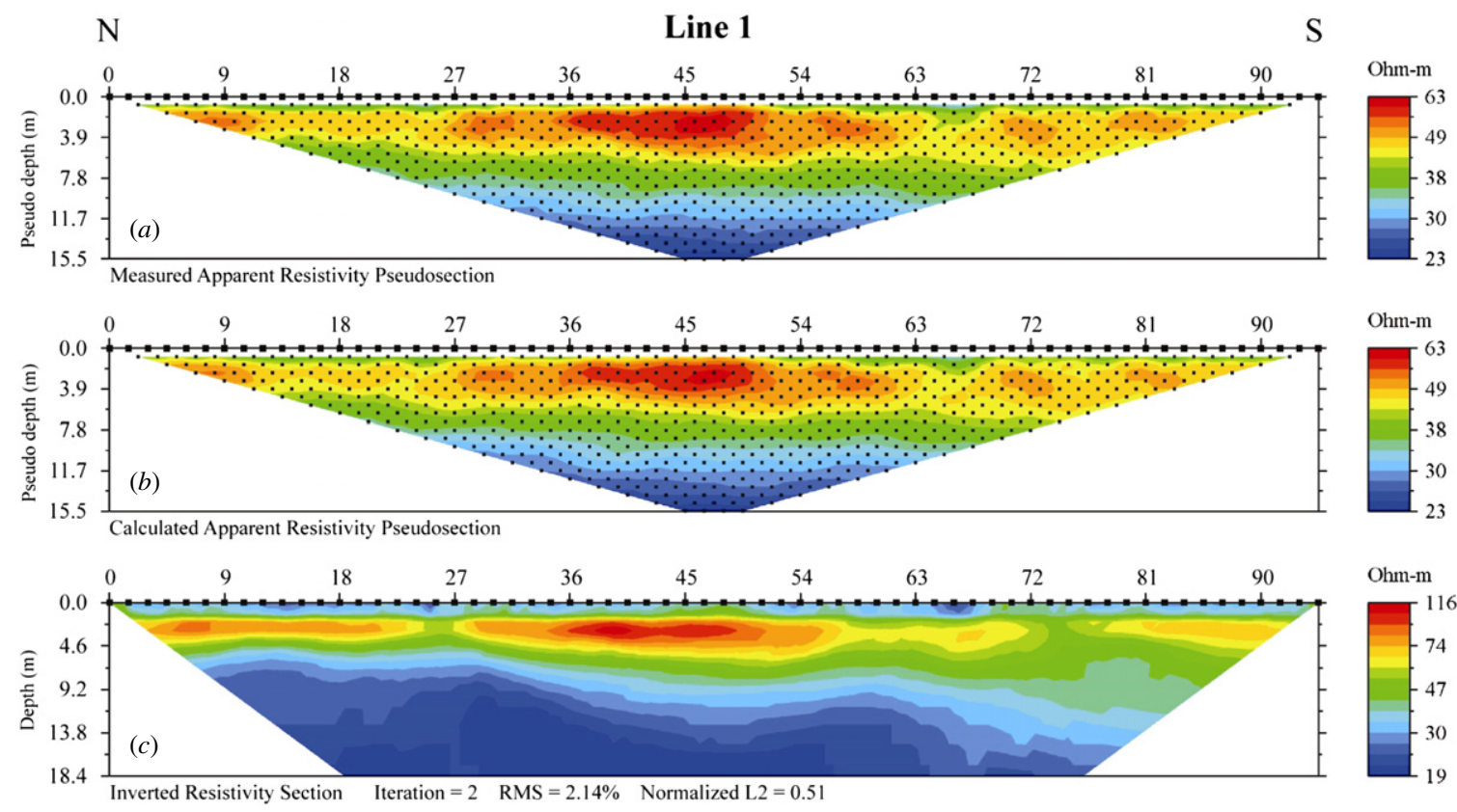

Figure 3. ERP results of line 1. (a) Measured apparent resistivity. Solid squares represent electrodes and dots are data points. (b) Calculated apparent resistivity due to the inverted resistivity models shown in $(c)$. (c) The inverted resistivity model.
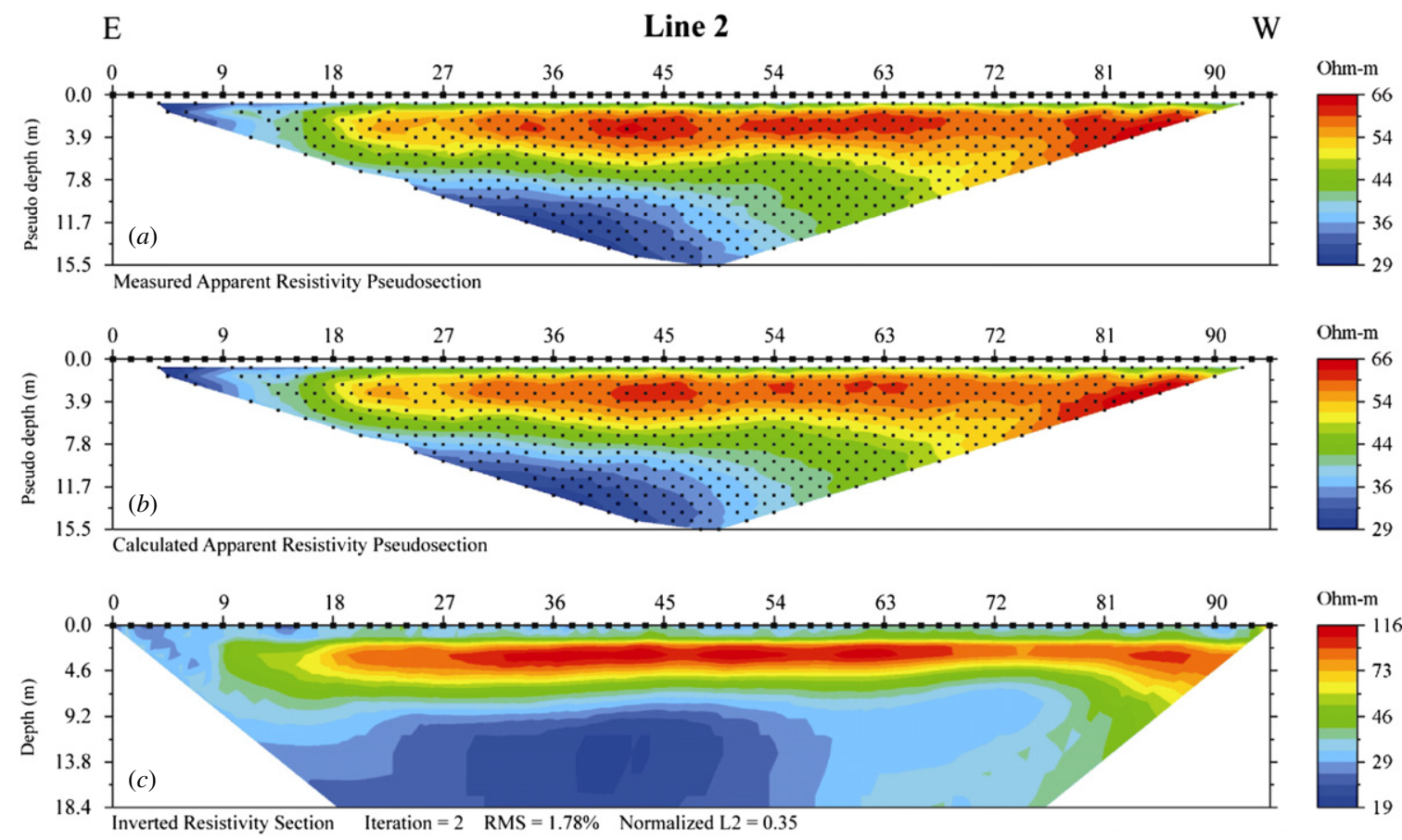

Figure 4. ERP results of line 2. (a) Measured apparent resistivity. Solid squares represent electrodes and dots are data points. (b) Calculated apparent resistivity due to the inverted resistivity models shown in $(c)$. (c) The inverted resistivity model.

No ash was found. The relatively low resistivity around the station was due to higher levels of clayey soil. This borehole confirmed that the volcanic ash body terminates around the station at $60 \mathrm{~m}$ on line 3. Borehole $\mathrm{H} 2$ was drilled at the station at $9 \mathrm{~m}$ on line 4 and with a TD of $7.5 \mathrm{~m}$. About a $0.3 \mathrm{~m}$ thick ash layer was found at a depth between 2.1 and
$3 \mathrm{~m}$. Borehole $\mathrm{H} 3$ was drilled at the station at $30 \mathrm{~m}$ on line 4 and with a TD of $7.5 \mathrm{~m}$. About $1.5 \mathrm{~m}$ of ash was found at a depth between 2.1 and $3.9 \mathrm{~m}$.

Borehole results of $\mathrm{H} 2$ and $\mathrm{H} 3$ confirmed the ERP interpretation that the ash body (a layer in red in figure $8(d)$ ) pinches out towards the north along line 4 . Borehole $\mathrm{H} 4$ was 

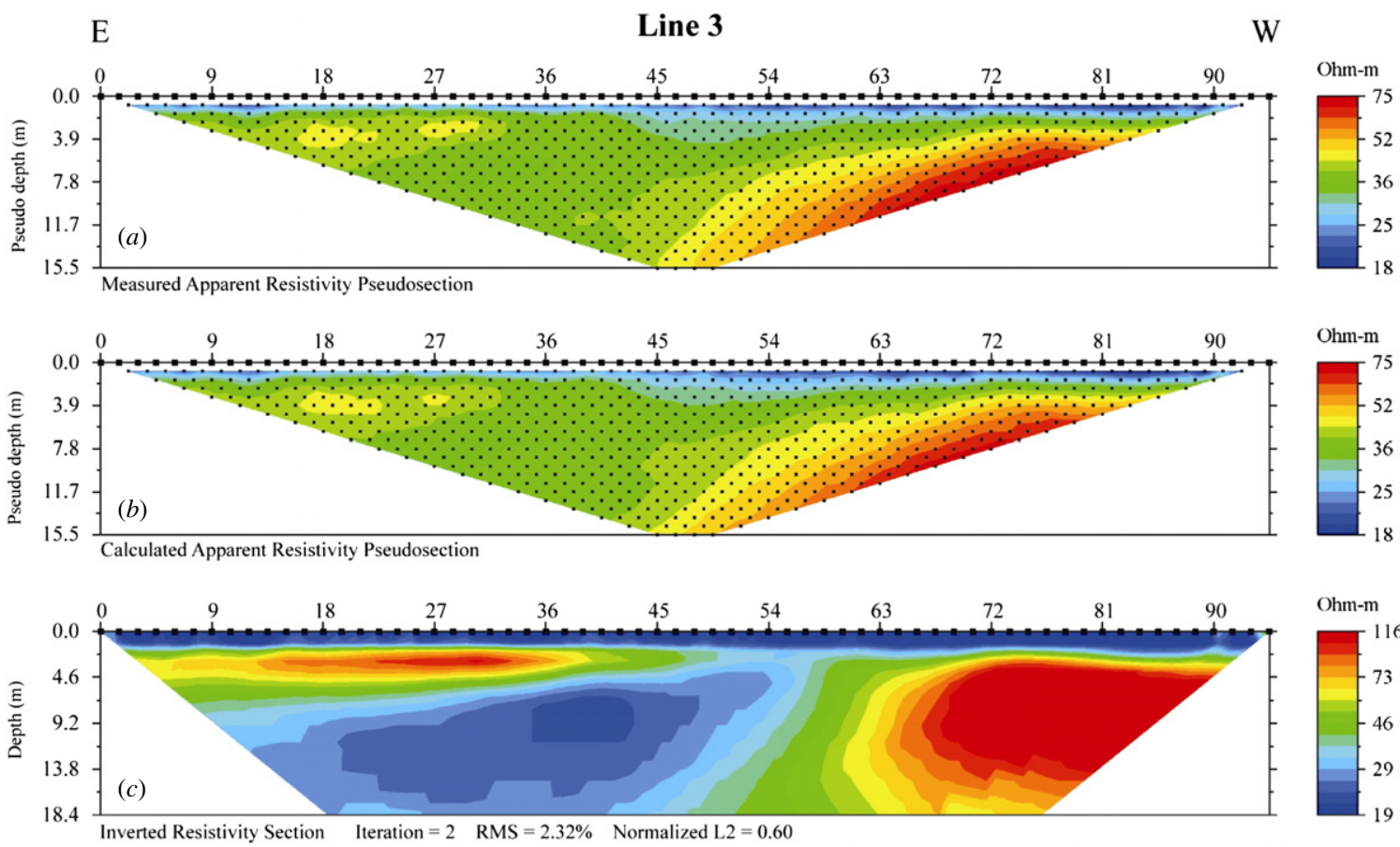

Figure 5. ERP results of line 3. (a) Measured apparent resistivity. Solid squares represent electrodes and dots are data points. (b) Calculated apparent resistivity data due to the inverted resistivity models shown in $(c)$. (c) The inverted resistivity model.
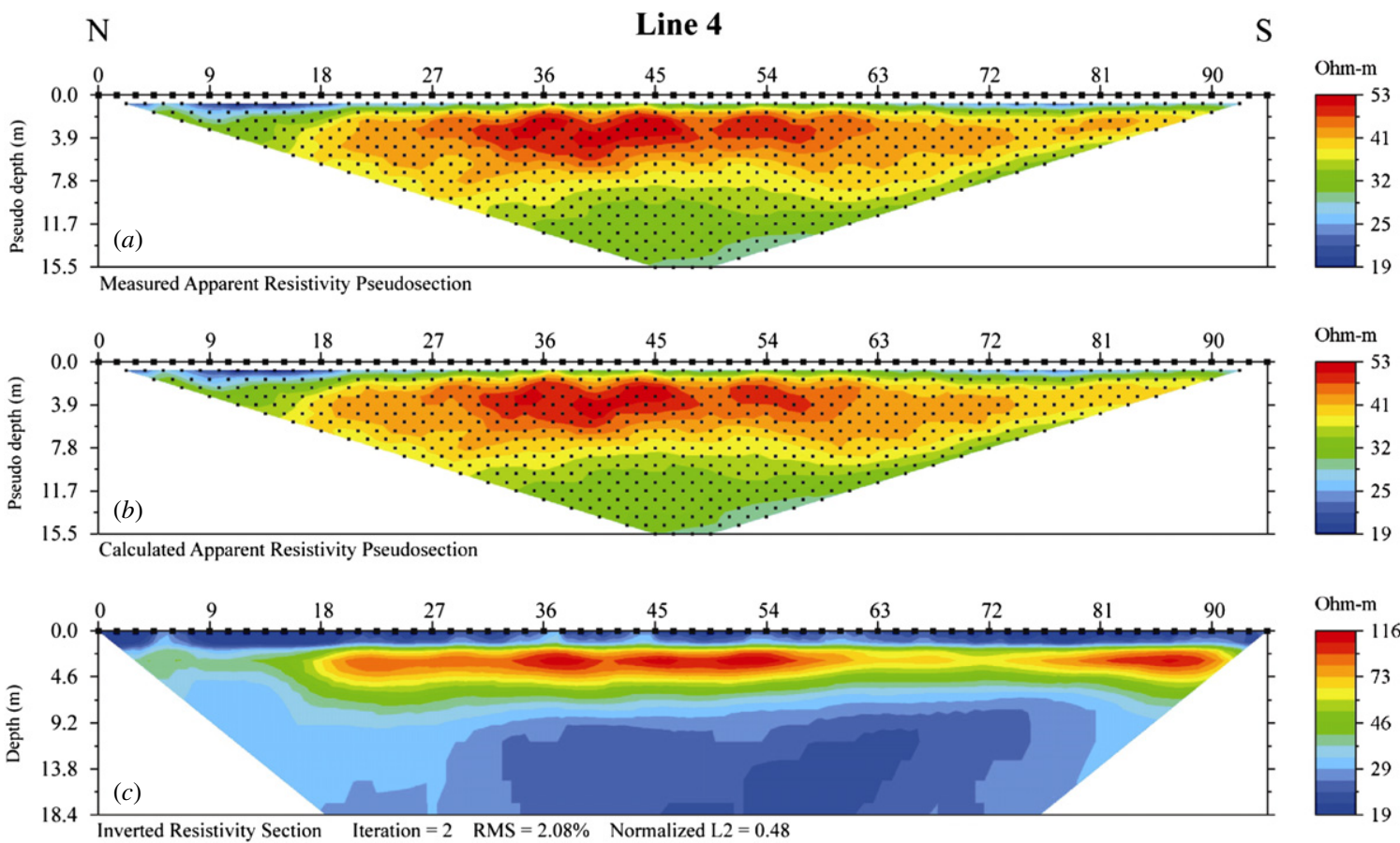

Figure 6. ERP results of line 4. (a) Measured apparent resistivity. Solid squares represent electrodes and dots are data points. (b) Calculated apparent resistivity data due to the inverted resistivity models shown in $(c)$. (c) The inverted resistivity model.

drilled at the station at $52.5 \mathrm{~m}$ on line 4 with a TD of $7.5 \mathrm{~m}$. Borehole samples were recovered from the depth interval between 1.5 and $3.3 \mathrm{~m}$ with soil from depth 1.5 to $2.1 \mathrm{~m}$ and colluvial deposits from depth 2.1 to $3.3 \mathrm{~m}$. No ash was found in $\mathrm{H} 4$ from depth 1.5 to $3.3 \mathrm{~m}$, which is inconsistent with electric resistivity interpretations that suggest volcanic ash should be present at the station at $52.5 \mathrm{~m}$ on line 4 from depth around 2.1 to $3.9 \mathrm{~m}$ as borehole $\mathrm{H} 3$ suggested. 

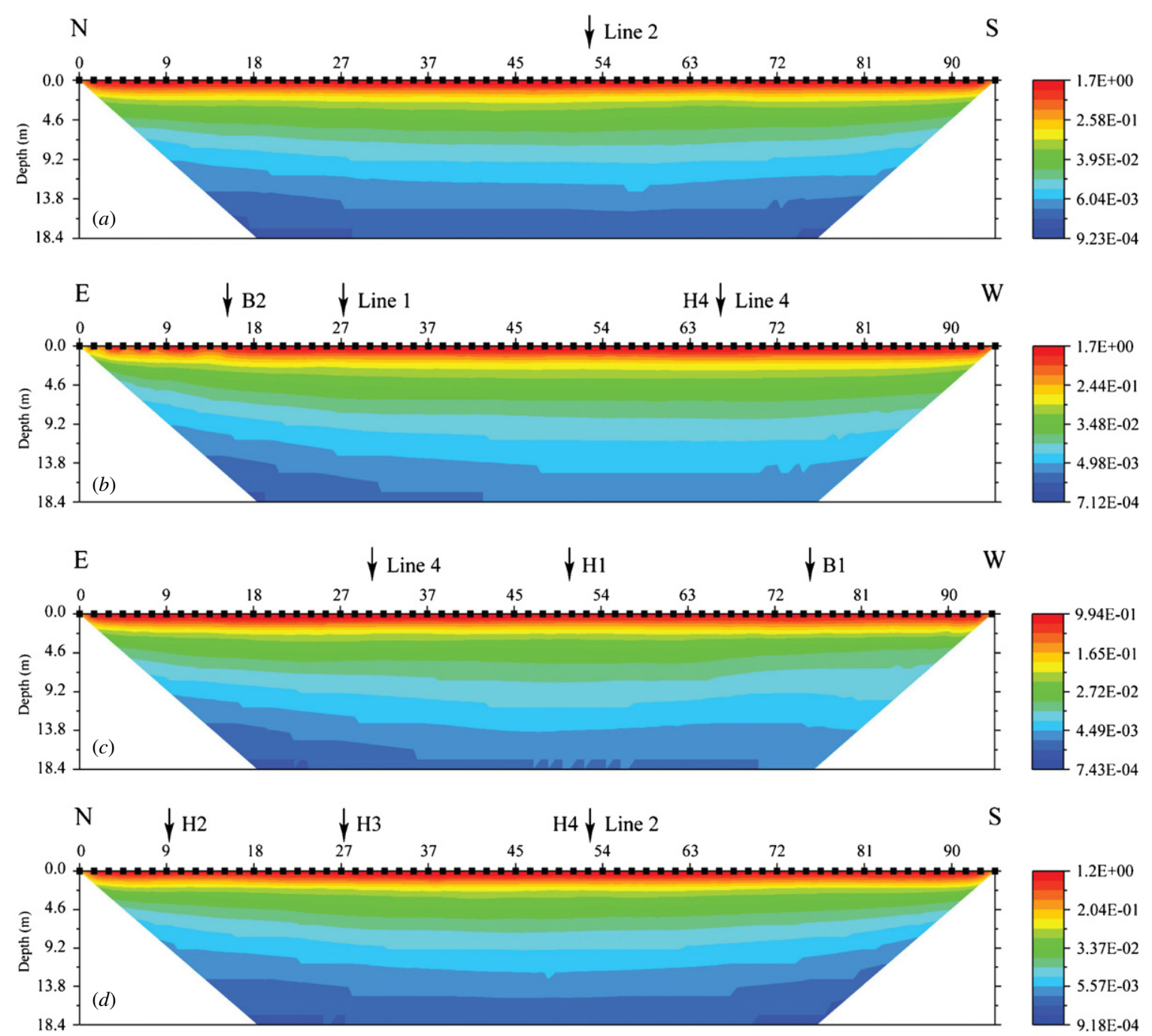

Figure 7. Pseudo model sensitivity of four lines. (a) Model sensitivity of line 1. (b) Model sensitivity of line 2. Borehole B2 is located $3 \mathrm{~m}$ north of line 2. (c) Model sensitivity of line 3. (d) Model sensitivity of line 4.

A possible reason that the ash is locally missing in $\mathrm{H} 4$ is that it was locally cut out by a small gully that was backfilled by the colluvium. This gully might be small enough to have not materially affected the imaging on line 4 due to horizontal smear effects of ERP, or volcanic ash could be present at a deeper depth. Drilling results of $\mathrm{H} 2, \mathrm{H} 3$, and $\mathrm{H} 4$ indicate that a thinner layer $(1.2$ to $1.5 \mathrm{~m})$ of ash is present between the stations at 24 and $50 \mathrm{~m}$ (figure $8(d)$ ).

Non-uniqueness of geophysical inversion (Menke 1984) and 3D effects (Yang and Lagmanson 2006) may be other reasons for the ash locally missing in H4. Occam's inversion (deGroot-Hedlin and Constable 1990) was employed in the software (AGI 2005). What we obtained from Occam's inversion of apparent resistivity data are smoothed resistivity models. Because the smoothed resistivity models possess higher model accuracy at a cost of reduced model resolution, some small (detailed) features may be missing from these inverted models. As discussed by Yang and Lagmanson (2006), due to a 3D nature of electrical current, a 2D resistivity imaging technique would be more likely to produce false anomalies because the objects which did not intersect the imaging plane would be folded onto the $2 \mathrm{D}$ inverted cross section.

The utility of ERP over a traditionally designed grid drilling becomes obvious in terms of their associated costs and environmental risks. Permitting, drilling and completing a borehole to $10 \mathrm{~m}$ has a wide range of potential expenses that are strongly dictated by where and when the borehole is planned. For purposes of this comparison, the cost of acquiring a borehole will be estimated for an area with no governmental or residential constraints, no permitting requirements and no environmental concerns. In an unconsolidated setting, installation of a borehole and core sampling will cost around $\$ 60-\$ 90$ per metre plus mobilization which generally runs around $\$ 1000$ for a local crew. For the study area, a minimum of ten holes is needed to define the volcanic body, which will cost around $\$ 7000$ to $\$ 10000$. Acquiring the four lines of ERP data requires $8 \mathrm{~h}$ for two people including set-up and break-down costing around $\$ 500$. Mobilization and data processing would cost another $\$ 500$. Based on these 

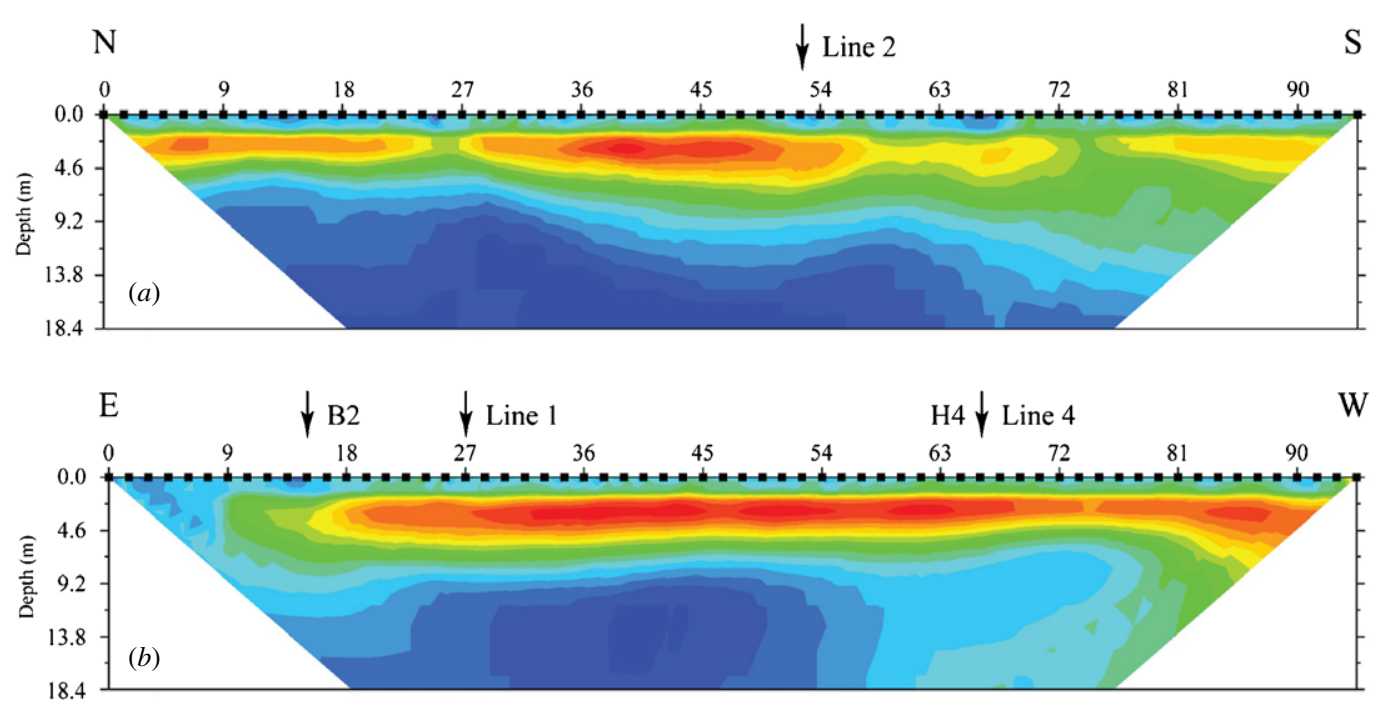

W
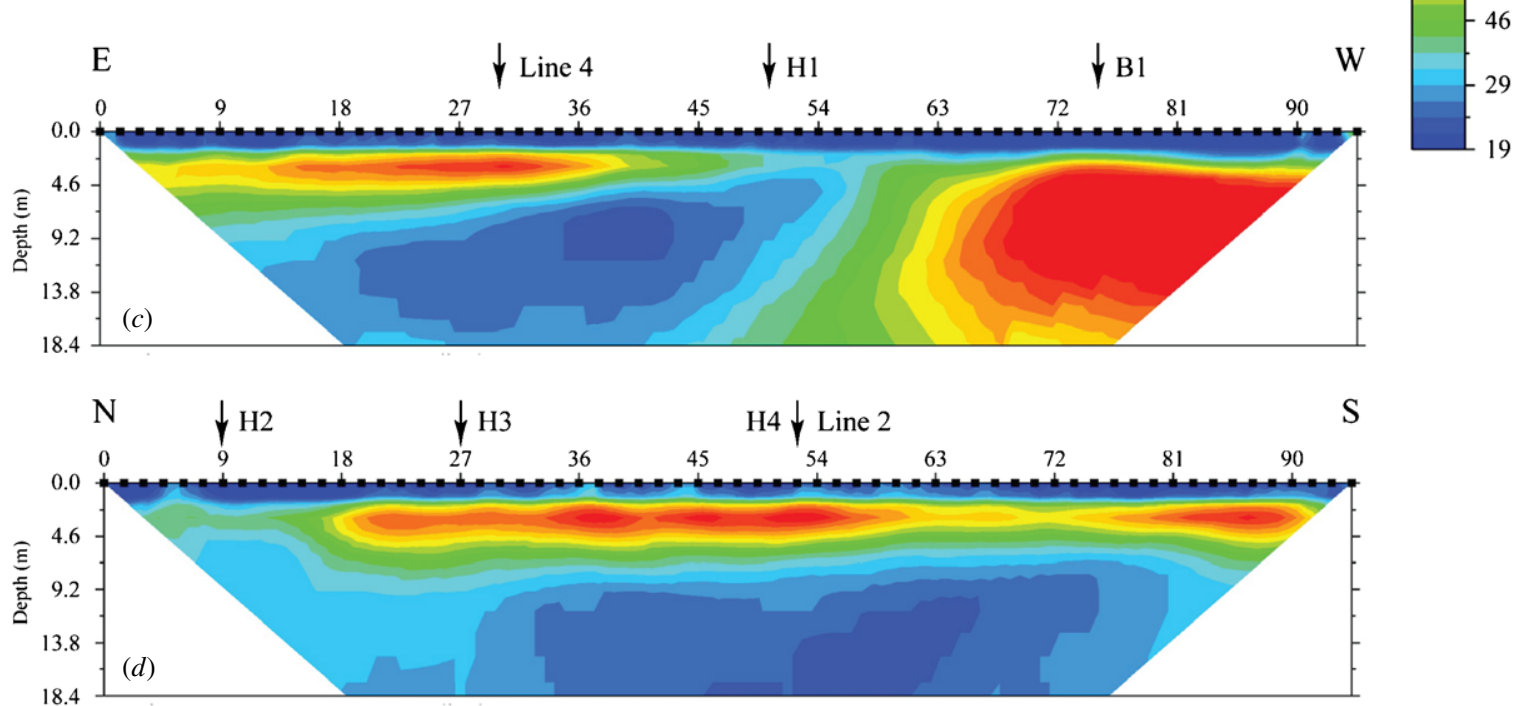

Figure 8. Inverted models with borehole locations and cross-points of tied lines. (a) Inverted resistivity of line 1. (b) Inverted resistivity of line 2. Borehole B2 is located $3 \mathrm{~m}$ north of line 2. (c) Inverted resistivity of line 3. (d) Inverted resistivity of line 4.

figures, ERP may only cost $15 \%$ of a traditionally designed grid drilling in defining the volcanic body. It must be kept in mind that this represents the best case scenario for a designed grid drilling velocity profile. Routinely health and environmental concerns play a major role that could potentially run the cost of a designed grid drilling up by orders of magnitude.

\section{Conclusions}

ERP surveys proved to be feasible in defining a drill-confirmed volcanic ash body at this testing site. The model sensitivity information (figure 7) indicates that inverted models possess sufficient resolving power down to a depth of $7 \mathrm{~m}$ and are fairly consistent in terms of horizontal resolution along the four lines. The bottom of most volcanic ash bodies in the study area is less than $7 \mathrm{~m}$. The lateral extent and general thickness were determined and confirmed along most lines by incorporating borehole data. Based on ERP and drill information, the boundaries of the mineable ash bed resources clearly are limited by the positions of buried cutbank scarps (figure 1), steeply inclined former stream banks that were cut downward into the upland stratigraphy and cut even further downward into the chalks of the Niobrara Formation, the local Cretaceous bedrock. These cutbank scarps bound the thick ash deposit currently being mined and a thinner ash deposit that rests on a higher buried stream terrace level to the east of the mine. The electric resistivity profiling proved to be very successful in imaging the location of the buried cutbank scarps. The area determined by the approximation boundary is about $4200 \mathrm{~m}^{2}$ (figure 9). Assuming a thickness of $1.5 \mathrm{~m}$ at borehole $\mathrm{H} 3$, the volume of ash in the study area is $6300 \mathrm{~m}^{3}$. By incorporating ERP with a minimal number of optimally placed borings, the volume and quality of the ore body could be established at less cost (about 15\% of a traditional designed grid drill) and with greater accuracy than a traditionally designed grid drilling programme. 


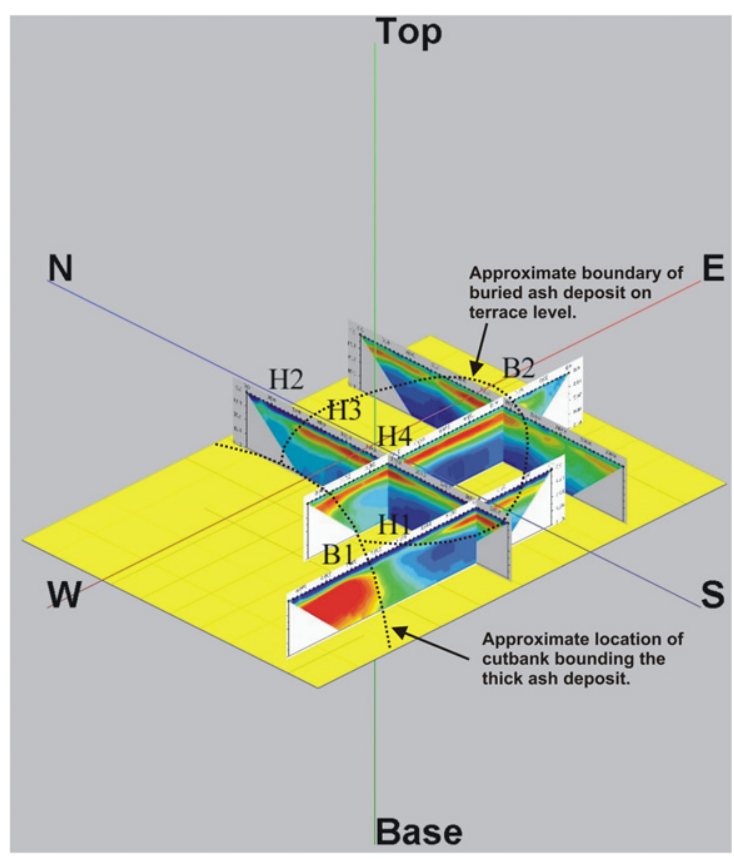

(a)

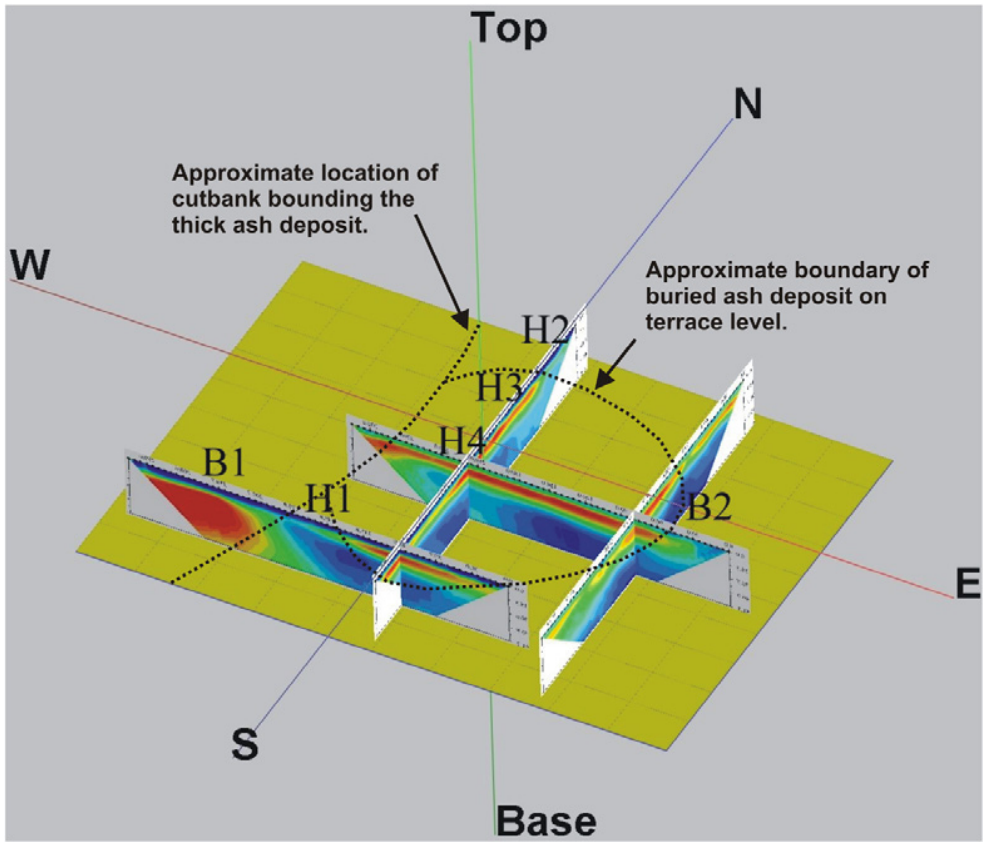

(b)

Figure 9. Fence diagrams with borehole locations and the interpretation of the boundaries of volcanic ash bodies. (a) A view from a southwest direction. (b) A view from a southeast direction.

\section{Acknowledgments}

We thank Joe Anderson, Brett Wedel, Anthony Wedel, Brett Bennett, Shelby Peterie, Joe Kearns and Justin Schwarzer of the Kansas Geological Survey (KGS) for acquiring electric resistivity data and GPS data and for performing borehole verifications, Marla Adkins-Heljeson of KGS for editing the manuscript, and Mary Brohammer of KGS for figure preparation. We are grateful to two anonymous reviewers for their constructive comments and suggestions; the work is significantly improved because of it.

\section{References}

AGI 2005 EarthImager, 2D Resistivity and IP Inversion Software: Instruction Manual (Saint Antonio, TX: Advanced Geosciences, Inc.)

Behiry M G and Hanafy S M 2000 Geophysical surveys to map the vertical extension of a sinkhole: a comparison study Symp. on the Application of Geophysics to Engineering and Environmental Problems (SAGEEP-2000, Arlington, VA, February 2000) ed M H Powers et al (Environmental and Engineering Geophysical Society) pp 341-50

Benson A K, Payne K and Stubben M A 1997 Mapping groundwater contamination using dc resistivity and VLF geophysical methods-a case study Geophysics $\mathbf{6 2} 80-6$

Bernard J and Leite O 2004 Multi-electrode resistivity imaging for environmental applications Progress in Environmental and Engineering Geophysics: Proc. 2004 Int. Conf. on Environmental and Engineering Geophysics (ICEEG) (Wuhan, China, 6-9 June) ed C Chen and J Xia (Monmouth Junction, NJ: Science Press USA) pp 317-22

Chakravarty D, Roy S and Das P K 2005 DC resistivity of alumina and zirconia sintered with TiC Bull. Mater. Sci 28 227-31

Dawson C B, Lane J W Jr, White E A and Belaval M 2002 Integrated geophysical characterization of theWinthrop landfill southern flow path, Winthrop, Maine Symp. on the Application of Geophysics to Engineering and Environmental Problems (SAGEEP) 2002 Annual Meeting of EEGS (Las Vegas, NV, 10-14 February 2002) available on CD

deGroot-Hedlin C and Constable S 1990 Occam's inversion to generate smooth, two-dimensional models from magnetotelluric data Geophysics 55 1613-24

Edwards L S 1977 A modified pseudosection for resistivity and IP Geophysics 42 1020-36

Hennig T, Weller A and Canh T 2005 The effect of dike geometry on different resistivity configurations $\mathrm{J}$. Appl. Geophys. 57 278-92

Loke M H 2001 Tutorial: 2D and 3D electrical imaging surveys http://www.geoelectrical.com (accessed 13 March 2001)

Lund E D, Christy C D and Drummond P E 2000 Using yield and soil electrical conductivity (ec) maps to derive crop production performance information: [CD-ROM computer file] Proc. of the 5th Int. Conf. on Precision Agriculture (Minneapolis, MN, ASA, CSSA, and SSSA, 16-19 July 2000) ed P C Robert et al

Menke W 1984 Geophysical Data Analysis-Discrete Inversion Theory (New York: Academic))

Oldenburg D W and Li Y 1999 Estimating depth of investigation in dc resistivity and IP surveys Geophysics 64 403-16

Olhoeft G R 1981 Electrical properties of rocks Physical Properties of Rocks and Minerals: McGraw Hill/CINDAS Data Series on Material Properties (New York: McGraw-Hill) chapter 9, pp 257-329

Reynolds J M 1997 An Introduction to Applied Environmental Geophysics (West Sussex, England: Wiley) 796 p

Tsourlos P I, Szymanski J E and Tsokas G N 1999 The effect of terrain topography on commonly used resistivity arrays Geophysics 64 1357-63

Wiggins R A 1972 The general linear inverse problem: Implication of surface waves and free oscillations for Earth structure Rev. Geophys. Space Phys. 10 251-85

Wolfe J P, Richard H, Hauser E and Hinks J 2000 Identifying potential collapse zones under highways Proc. Symp. on the Application of Geophysics to Engineering and Environmental 
Problems (SAGEEP), Annual Meeting of the Environmental and Engineering Geophysical Society (EEGS) (Arlington, VA, 20-24 February 2000) pp 351-8

Xia J and Miller R D 2007 Integrated geophysical surveyin defining subsidence features on a golf course J. Geophys. Eng. 4 443-51

Yang X and Lagmanson M 2006 Comparison of 2d and 3d electrical resistivity imaging methods Proc. Symp. on the Application of
Geophysics to Engineering and Environmental Problems (SAGEEP), Annual Meeting of the Environmental and Engineering Geophysical Society (EEGS) (Seattle, WA, 2-6 April 2006) pp 585-94

Zohdy A A R, Eaton G P and Mabey D R 1974 Application of surface geophysics to ground-water investigations Techniques of Water-Resources Investigations of the United States Geological Survey book 2, chapter D1, 116 pp 